\title{
Bases biológicas de la memoria en el aprendizaje
}

José Luis Quintanar Stephano ${ }^{1}$

\section{Resumen}

Aunque no es el único elemento que interviene, la memoria juega un papel central en los procesos de aprendizaje dentro y fuera del ámbito escolar. En este trabajo se hace una revisión de los factores que pueden modificar la calidad de la memoria desde su sustrato neurológico. Una vez definida la memoria, revisado sus tipos, y descritos los mecanismos neuro-fisiológicos que la posibilitan, se abordan los factores factores que la condicionan: la nutrición, el estrés, la concentración, la motivación y la ejercitación.

Palabras clave: memoria; aprendizaje; sistema nervioso; fisiología; educación superior.

1 Universidad Autónoma de Aguascalientes, jlquinta@correo.uaa.mx 


\section{Abstract}

Although it is not the only element at stake, memory plays a central role in learning processes inside and outside the school environment. In this work, a review is made of the factors that can modify the quality of memory from its neurological substrate. Once memory is defined, its types reviewed, and the neuro-physiological mechanisms that make it possible have been described, the factors that condition it are addressed: nutrition, stress, concentration, motivation and exercise.

Keywords: memory; learning; nervous system; physiology; higher education.

Es recurrente escuchar entre los estudiantes la opinión de que "yo primero entiendo y luego lo memorizo", como que el aprendizaje a base de "machetear" no se les da en relación a su inteligencia, estableciendo una jerarquía de primero aprendo y luego memorizo ${ }^{2}$. Sin embargo, el establecimiento de la base de datos implica la adquisición de información, su procesamiento y luego su evocación para después darle un sentido de aplicación; es decir, primero está la memoria y luego su manifestación, que es el aprendizaje.

2 Para un abordaje más detallado del tema, recomendamos consultar a Quintanar, Calderón y González (2016). 
Es complejo definir el término de memoria. Una manera relativamente sencilla pudiera ser "la capacidad de almacenar información" o alguna de las más complejas "función que permite a un individuo codificar o registrar, almacenar y recuperar la información de eventos pasados y que implica conexiones sinápticas entre las neuronas".

Con el avance tecnológico, quizá sea más sencillo entender lo que es la memoria si se compara con los elementos de una computadora. Si pensamos en los procesadores y las memorias, estas últimas son el elemento donde se guarda la información y los procesadores son aquellos que emplean esa infor-mación para definir una respuesta de acuerdo a un programa específico. Así, para tratar de entender el fenómeno de la memoria, el cerebro podría ser el equivalente a la computadora donde se almacena la información.

Cuando se tiene a un estudiante de memoria brillante (que no es lo mismo que inteligencia brillante), ¿qué puede tener de diferente respecto al resto de los demás estudiantes?, ¿repite más las cosas, se concentra más cuando percibe la información, tiene una motivación mayor o presenta un volumen ence-fálico más grande o tiene una genética distinta?

Es importante previamente analizar qué ocurre con el fenómeno de la mnésis en un estudiante "normal".

Cuando se adquiere información en cuanto al conocimiento abstracto, es decir, de memoria cognitiva, 
(existe la clasificación que incluye dos más: la memoria motora y la sensitiva), que es la más empleada a nivel de la educación superior, dicha información pasa a diferentes áreas del encéfalo siendo las más impor-tantes la corteza cerebral, el hipocampo y la amígdala (sistema nervioso). Estos órganos están constituidos por neuronas y células de apoyo (gliales). Dichos complejos celulares forman redes que establecen contactos entre sí llamados sinapsis y las estructuras que contactan pueden ser botones sinápticos o espinas dendríticas. La comunicación tiene lugar a través de mensajeros químicos llamados neurotransmisores, que son liberados cuando se dan cambios bioeléctricos en las neuronas. Es en este nivel es el que tienen lugar los procesos que llamamos memoria. Mirado a nivel neuronal, el fenómeno incluye eventos como el incremento de iones de calcio y potasio, la activación de algunas enzimas de las membranas neuronales conocidas como ATPasas, el incremento en la síntesis de proteínas, en el número de contactos sinápticos y en las espinas dendríticas, así como una liberación de neurotransmisores comparativamente mayor.

Transformada en señales bioeléctricas, la información llega a diferentes áreas del encéfalo, pudiendo generar tres tipos de memoria en función del tiempo de retención de información. En primer lugar, está la memoria a corto plazo, cuya duración es cuestión de minutos y solo implica cambios en los iones y en la liberación de neurotransmisores. En segundo lugar, tenemos 
la memoria a mediano plazo, que supone horas, días incluso; un tipo de memoria en la que se activan iones, neurotransmisores y enzimas. Final-mente, está la memoria a largo plazo, cuya duración va desde algunos días hasta la totalidad de la existencia. En este tipo de memoria intervienen todos los elementos anteriormente mencionados y se incluye además la expresión de proteínas junto con la emergencia de contactos sinápticos nuevos. Es en éste último caso en el que se presentan cambios morfo-lógicos que incluso se pueden valorar experimen-talmente en animales de laboratorio o en casos pato-lógicos como el Alzheimer.

El estudiante de memoria brillante es aquél que presenta la infraestructura neurológica requerida para una dinámica comparativamente más eficiente y fluida en la memoria a corto, medio y largo plazo. Esto supone una velocidad de conducción nerviosa (flujo de iones y liberación de neurotransmisores) mayor, el aumento de la actividad enzimática y en la síntesis de proteínas y, finalmente, el incremento del número de contactos sinápticos.

Se puede decir que este es el sustrato neuro-lógico que puede marcar la diferencia entre la memoria de un individuo normal y la de uno brillante. Sin embargo, ¿se puede modificar la calidad de la memoria en ambos casos?; es decir, ¿se puede incrementar la capacidad de memoria en un estudiante "normal" o bien, se puede perder cierta calidad en ella de manera espontánea o natural en un estudiante brillante? 
La respuesta es afirmativa: existen factores que pueden modificar sensiblemente la calidad de la memoria, es decir alterar el sustrato neurológico como a continuación se analiza.

Uno de los factores a considera es la nutrición. Como pasa con la gran mayoría de funciones bioló-gicas, la nutrición es fundamental para proveer a las células de los nutrientes energéticos, estructurales u otros que requieren para su actividad. Sabemos que un estudiante con dificultades de nutrición presentará alteraciones intelectuales y la función de la memoria no sería una excepción. Cuando el aporte de carbohi-dratos o la síntesis de proteínas a base de aminoácidos llegan a disminuir, la actividad neuronal se ve afectada, afectando la calidad de la memoria y del aprendizaje. Aminoácidos como la fenilalanina, el ácido glutámico y el triptófano están directamente relacionados con la calidad de la memoria y éstos suelen encontrarse en los alimentos de consumo cotidiano.

Otro factor es el estrés. En fisiología, el estrés es definido como una alteración en el medio interno, en el ambiente donde las células realizan sus funciones. La alteración pone en riesgo la homeostasis o equilibrio. Existen diversos agentes estresantes biológicos y psíquicos que pueden desencadenar respuestas innatas 0 aprendidas. Ante una situación de estrés aprendida, en un examen o al enfrentar la pregunta de un profesor inquisidor, por ejemplo, la memoria a corto plazo se bloquea (disminuyen el flujo iónico y los neurotrans-miso- 
res). Con el estrés crónico, la secreción de hormo-nas como la adrenalina y el cortisol aumenta, lo que ocasiona una disminución de la actividad bioélectrica de las neuronas y las espinas dendríticas, afectando la calidad de la memoria y por consiguiente, la del aprendizaje. Liberar la carga emocional o dormir bien son formas de reducir el estrés y así reconstituir la calidad de las respuestas neurológicas dependiendo de los acúmulos iónicos o de neurotransmisores, agilizan-do los circuitos existentes y facilitando la memoria.

La concentración es otro de los factores a con-siderar. Concentrarse favorece de manera significativa la consolidación de la información. Las rutas neuro-lógicas establecidas para los componentes mnemotéc-nicos sin distracciones establecen contactos sinápticos más específicos en los que la evocación de los recuerdos sea más efectiva y tenga lugar con menor esfuerzo. Al tomar en cuenta la concentración, hay otra forma de clasificar de los tipos de memoria. Tenemos por un lado la memoria explícita o declarativa, que está vinculada con la conciencia; es decir, que se realiza dándose cuenta del evento y depende para su conservación del hipocampo, así como de otras partes de los lóbulos temporales en la corteza cerebral. Por otro lado, está la memoria implícita o no declarativa, que no incluye la participación de la conciencia y cuya retención casi nunca comprende el "procesamiento" en el hipocampo, sino en otras áreas encefálicas como el cerebelo, el tálamo o incluso la médula espinal. Este tipo de memoria 
incluye la clase de habilidades y hábitos que, una vez adquiridos, se tornan automáticos, inconscientes (e.g., andar en bicicleta o conducir un automóvil estándar). La memoria a corto, mediano y largo plazo quedarían incluidas en la memoria explícita; la conciencia, por acción de la voluntad, fija su atención a una información en concreto y favorece la memoria cognitiva o conceptual.

La motivación, otro factor, remite a lo que impulsa a un individuo a llevar a cabo determinada actividad hasta lograr el propósito planteado. "El interés tiene pies", dice el refrán popular; si hay una recompensa placentera o un castigo lo suficientemente intenso, el interés por retener la información se incrementa de manera significativa. El caso del estudiante desmo-tivado es casi un caso de amnesia consciente. Por ello, mantener motivados a los estudiantes es un reto constante para los docentes. De otro modo, se dificulta inducir la retención de la información mientras sea necesaria, útil. Las neuronas del cerebro anterior, en el área tegmentaria ventral y el núcleo accumbens, participan en los fenómenos motivacionales: el placer, la recompensa, la adicción, el terror, la risa; áreas conocidas como el centro de placer o recompensa del cerebro.

La corteza frontal del cerebro, el hipocampo y la amígdala participan en la memoria, proyectándose al núcleo accumbens por ciertas vías excitadoras. Por ello, la motivación —la emoción-guarda una estrecha relación con la calidad de la memoria. Cuando existe 
interés en la información, cuando es importante o tiene valor, es más probable que se recuerde en relación a aquella que tenga menor valor, dado que una es potencialmente más resolutiva que la otra.

Ejercitar la memoria, practicarla activamente como reto, favorece la capacidad de la misma para otras ocasiones. En sentido contrario, no realizar esfuerzos por recordar información, dejándola a la espontaneidad -abulia del recuerdo-, costará más trabajo para las siguientes ocasiones. Al ejercitar la memoria se produce una serie de eventos neurológicos conocidos como "facilitación" o "sensibilización". Con base en estos eventos, las neuronas involucradas en el proceso se hacen más fácilmente excitables de modo que cuando se les "solicite" recordar determinada información, el esfuerzo será menor. Como dice el refrán, "órgano que no se utiliza, se atrofia". Acciones en el estudio como: esquematizar, subrayar, repetir, asociar, orga-nizar los apuntes, etc., favorecen la memoria y, por ende, el aprendizaje. Aunque guarden relación directa con cambios neuronales, son formas de aprender a aprender que se inscriben en la experiencia.

Hay que apuntar aquí que el volumen cerebral no es un factor que influya en la calidad de la memoria de un estudiante. Por otra parte, no está claro si existe un substrato genético de la memoria. Dicho de otro modo, no sabemos si padres con buena memoria necesa-riamente la hereden a sus hijos. 
Como conclusión, un estudiante "normal" que se encuentre desmotivado, estresado, desconcentrado, desnutrido, con abulia del recuerdo, probablemente no será capaz de recordar el nombre de su profesor al final del curso. Es posible que en la corteza cerebral, hipocampo y amígdala de este estudiante los iones de las neuronas se haya ido por otro lado, que los neurotransmisores no hayan sido liberados adecuada-mente, que las enzimas no rompan su substrato, que las proteínas no se hayan sintetizado correctamente y que el núcleo accumbens no esté suficientemente motivando.

\section{Referencias}

Quintanar, J. L, Calderón, D. y González, M. L. (2016). ¿Qué es bueno para la memoria?. Aguascalientes: UAA. Recuperado de https://editorial.uaa. $\mathrm{mx/}$ docs/zombis memoria.pdf 
Esta obra está bajo una

Licencia Creative Commons Atribución-NoComercial-Compartirlgual 4.0 Internacional

Usted es libre de compartir o adaptar el material en cualquier medio o formato bajo las condiciones siguientes: (a) debe reconocer adecuadamente la autoría, proporcionar un enlace a la licencia e indicar si se han realizado cambios; (b) no puede utilizar el material para una finalidad comercial y (c) si remezcla, transforma o crea a partir del material, deberá difundir sus contribuciones bajo la misma licencia que el original.

Resumen de la licencia https://creativecommons.org/licenses/by-nc-sa/4.0/deed.es_ES

Texto completo de la licencia https://creativecommons.org/licenses/by-nc-sa/4.0/legalcode 